\title{
LA DIFÍCIL DETERMINACIÓN DE LA RESIDENCIA HABITUAL DEL MENOR EN LOS SUPUESTOS DE RESPONSABILIDAD PARENTAL
}

\section{THE COMPLEX TASK OF DETERMINING THE HABITUAL RESIDENCE OF THE CHILD IN PARENTAL RESPONSABILTY CASES}

\author{
Nerea Magallon Elósegui \\ Profesora Investigadora Ramón y Cajal \\ Universidad del País Vasco (UPV/EHU) \\ ORCID ID: 0000-0003-3994-049X
}

Recibido: 16.06..2021 / Aceptado: 19.07.2021

DOI: https://doi.org/10.20318/cdt.2021.6297

\begin{abstract}
Resumen: La determinación de la residencia habitual como criterio para establecer la competencia de los tribunales europeos en materia de responsabilidad parental se ha convertido en una ardua cuestión que el Tribunal de Justicia de la Unión ha ido acotando a través de numerosa jurisprudencia. El carácter abierto y variable que la caracteriza dificulta la tarea de los operadores jurídicos, pero también nos permite atender caso por caso a las distintas variables derivadas del incremento de la movilidad geográfica en Europa.

Palabras clave: Derecho internacional privado, Derecho europeo de familia, Reglamento Bruselas II bis, responsabilidad parental, pensión de alimentos, criterios de competencia, residencia habitual.

Abstract: The determination of the connecting factor for concretizing the jurisdiction of the European courts in parental responsibility matters is a complex issue that the Court Of Justice of the Unión has been refined through the case law. The open and variable nature of the habitual residence of the child makes the work of legal practitioners somewhat complex, but it also allows us to deal with the different variables arising from the increase in geographical mobility in Europe on a particular case.

Keywords: Private International law, European family law, Regulation Brussels II bis, parental responsability, maintenance obligation, jurisdiction rules, habitual residence.

Sumario: I. Introducción: antecedentes y estado de la cuestión. II. La aplicación del Reglamento 2201/2003: una primera cuestión aparentemente redundante pero necesaria. III. El carácter accesorio y alternativo de la pensión alimenticia en aras a establecer el foro de competencia. IV. La residencia habitual: un concepto flexible y adaptable caso por caso. V. La perpetuatio jurisdictionis en el Reglamento Bruselas II bis. VI. Consideraciones finales.
\end{abstract}

\section{Introducción: antecedentes y estado de la cuestión}

1. En el Auto de la Audiencia Provincial de Barcelona, Sección 12, de 16 de noviembre de $2020^{1}$ que ha dado lugar a este comentario se plantean dudas acerca de la jurisdicción competente para

${ }^{1}$ Auto de la Audiencia Provincial de Barcelona, Sección no 12 de Resolución 3333/2021, Roj: AAP B 10309/2020. 
modificar las medidas concernientes al régimen de visitas y la pensión de alimentos sobre una menor, establecidas en sentencia previa de divorcio. Se trata de una alteración derivada del hipotético cambio de residencia de la menor que cursaba sus estudios en Rumania y que se establece con la madre en España. La madre actúa como demandante y solicita ante el foro español una modificación de la sentencia de divorcio que disuelve su vínculo matrimonial con el objeto de anular el régimen de visitas del demandado con su hija y de incrementar la pensión de alimentos que se impuso al padre por haber aumentado las necesidades de la menor.

2. El Juzgado de Primera Instancia rechaza su competencia en base a una interpretación de la residencia habitual de la menor que tiene en cuenta el último lugar donde ha cursado sus estudios. La demandante, y madre de la menor, recurre dicha decisión a la Audiencia Provincial de Barcelona que, sin embargo, tras realizar un análisis ponderado de las circunstancias del caso estima el recurso de apelación y concluye que la residencia de la menor se encontraba en España al momento de iniciarse el procedimiento y que, por tanto, son competentes los tribunales españoles.

3. El supuesto planteado nos va a permitir hacer un análisis que pone de manifiesto parte de las características de la regulación actual del Derecho de familia internacional y, en particular, del sistema europeo de responsabilidad parental; y a la vez para establecer una pequeña valoración de su situación ante la próxima entrada en vigor del Reglamento Bruselas II ter².

En primer lugar, hemos querido resaltar la complejidad del entramado normativo que convive en esta materia en el ordenamiento jurídico español y la importancia de delimitar los distintos instrumentos aplicables (II). Después se atiende a su fragmentación en diversos instrumentos jurídicos. Después, tomando como modelo la pensión alimenticia, se atiende a su fragmentación en diversos instrumentos poniendo de relevancia los diferentes intereses protegidos y las múltiples sensibilidades que subyacen bajo el Derecho de familia, (III). En segundo lugar, observamos que los distintos criterios hermenéuticos utilizados por ambos tribunales en el momento de determinar dónde se encuentra la residencia habitual de la menor al iniciar el procedimiento son un indicativo de las dificultades que puede comportar el criterio de competencia escogido por el Reglamento Bruselas II bis para establecer la jurisdicción en el ámbito de responsabilidad parental (IV); lo que nos lleva, en último lugar, a recordar brevemente la viabilidad de aplicar las excepciones de perpetuatio fori en aras satisfacer el interés del menor como principio clave del sistema (V).

\section{La aplicación del Reglamento 2201/2003: una primera cuestión aparentemente redundante pero necesaria}

4. Lo primero que debemos hacer al analizar la competencia de los tribunales españoles es determinar los instrumentos aplicables al caso, tal y como hace correctamente en este Auto la Audiencia Provincial de Barcelona. Los supuestos de crisis matrimoniales en los que se involucran menores originan una nueva organización de las relaciones conyugales y paterno- filiales que tiene efectos en múltiples ámbitos de la esfera familiar. La nueva organización de la familia requiere de la adopción de distintos tipos de medidas que se encuadran en un marco legislativo heterogéneo que, a pesar de su interconexión, ha seguido diferentes velocidades en el proceso de armonización europeo ${ }^{3}$. La sensibilidad congénita al Derecho de familia se ha traducido en una reglamentación compartimentada y fragmentada en múltiples instrumentos (con origen en distintas fuentes institucional, convencional y estatal) que dotan de cierta complejidad a la ordenación de la estructura familiar internacional en supuestos de crisis

\footnotetext{
2 Reglamento 1111/2019 relativo a la competencia, el reconocimiento y la ejecución de resoluciones en materia matrimonial y de responsabilidad parental y sobre la sustracción internacional de menores (Bruselas II ter), DOUE L 178, 2 de julio de 2019, que se aplica con carácter general a partir del 22 de julio de 2022 (art. 105).

3 R. Arenas Gracia, Crisis matrimoniales internacionales, De conflictum Legum, Universidade de Santiago de Compostela, Santiago de Compostela, 2004.
} 
matrimoniales ${ }^{4}$, a la par que obligan al operador jurídico a realizar una labor previa de delimitación de la normativa aplicable.

5. Precisamente, la Audiencia Provincial de Barcelona inicia su argumentación instaurando la norma que debe utilizar para examinar la competencia de los tribunales españoles a raíz del recurso de apelación interpuesto por la madre de la menor contra la resolución del Juzgado de Primera Instancia, que rechazaba su jurisdicción para conocer las modificaciones de la potestad parental sobre la misma por su hipotética residencia habitual en Rumania. A tales efectos, parte de la aplicación del Reglamento 2201/2003 del Consejo de 27 de noviembre 2003, relativo a la competencia, el reconocimiento y la ejecución de resoluciones judiciales en materia matrimonial y de responsabilidad parental (Bruselas II bis $)^{5}$ en calidad de norma europea, apelando a su prevalencia jerárquica en supuestos internacionales.

La aplicación del Reglamento Bruselas II bis no presenta dudas desde el punto de vista de su ámbito espacial puesto que se trata de examinar la competencia de las autoridades españolas en foro español. Y tampoco plantea problemas respecto a su ámbito de aplicación personal, en tanto la menor (que no llega a los 18 años $^{6}$ ) afectada por la modificación de las medidas de responsabilidad parental objeto de la demanda tiene la residencia habitual en España y anteriormente la tuvo en Rumania, ambos Estados miembros de la Unión (art. 61.a RBIIbis) ${ }^{7}$.

6. En segundo lugar, la Audiencia alude a la integración de las medidas solicitadas en el ámbito de aplicación material del Reglamento Bruselas II bis. La demanda que inicia el procedimiento y que ha dado lugar al Auto objeto de comentario, se refiere a dos materias distintas: régimen de visitas y alimentos; así que conviene recordar cual de ellas se subsume en el concepto de "responsabilidad parental" recogido en el Reglamento europeo. El Reglamento Bruselas II bis incluye una regulación completa de la competencia judicial en materia de responsabilidad parental, conforme a la que establece una regulación general que, por un lado, no se limita a los supuestos de responsabilidad parental incursos en crisis matrimoniales (Cdo. 5) y , por otro, a diferencia de su predecesor ${ }^{8}$, comprende a los denominados "hijos de la familia" sean comunes o no". Sin embargo, de las diferentes cuestiones que se pueden suscitar en los supuestos de crisis matrimoniales únicamente se ocupa de las vinculadas con la responsabilidad

${ }^{4}$ Como ponen de manifiesto, entre otros: A. Borrás, "From Brussels to Brussels bis" en K. Boele-Woelki y C. González Beilfuss (eds.), Brussels II bis: Its impact and Application in the Member States, Amberes /Oxford, Intersentia, 2007, pp. 3-22; J. Carrascosa GonzÁlez, "Cuestiones polémicas en el Reglamento 1347/2000” en A. L. Calvo Caravaca y J. L. Iriarte (eds.) Mundialización y familia, Madrid, Colex, 2001, pp. 213-239; F. GARAU Sobrino, "Notas sobre la colisión de fuentes de Derecho Internacional privado español sobre responsabilidad parental y protección del niño", $C D T, 2011$, vol. 3, No 1, pp. 282-289; A. Duran Ayago, "Ejercicio de los derechos de custodia y de visita en un mundo globalizado: riesgos y disfunciones especial referencia al forum divorti en el contexto europeo", A.L. Calvo Caravaca y J. Carrascosa González (dres.) Protección de menores y Derecho Internacional privado, Comares, Granada, 2019, pp. 91-102.

5 DOUE L338, de 23 diciembre de 2003.

${ }^{6}$ El concepto de menor no aparece definido en el Bruselas II bis, con lo que deberá interpretarse conforme a las legislaciones nacionales. Esto ha cambiado en el Reglamento 1111/2019 25 de junio, relativo a la competencia, el reconocimiento y la ejecución de resoluciones en materia matrimonial y de responsabilidad parental, y sobre la sustracción internacional de menores, (Bruselas II ter), DOUE L 178, 2 de julio de 2019, que ha incluido una definición de menor como toda persona de menos de 18 años (art. 2.6). A tales efectos la "Guía practica para la aplicación del RBIIBis" hace un apunte sobre su aplicación a menores emancipados según la legislación nacional y extrae de su ámbito de aplicación las medidas adoptadas sobre personas emancipadas, p. 19; en contra P. ORejudo Prieto de los Mozos, "Diez años de aplicación e interpretación del Reglamento Bruselas II bis sobre crisis matrimoniales y responsabilidad parental (Análisis de los aspectos de competencia judicial internacional)", $L a$ Ley Unión Europea, n $^{\circ}$ 21, diciembre 2014, pp. 1-19, p. 5.

7 Sobre cuestiones problemáticas vinculadas a la determinación del ámbito de aplicación del RBII bis, vid., A. QuiÑonES Escamez, “¿Cuándo se aplica el Reglamento Bruselas II bis?, Revista de Derecho Comunitario, № 29, 2008, pp. 457-482.

${ }^{8}$ Reglamento 1347/2000, 29 mayo de 2000, relativo a competencia, reconocimiento y ejecución en materia matrimonial y de responsabilidad parental, DOCE $\mathrm{n}^{\circ} 160$, de 30 de junio de 2000.

9 Es menester recordar que el Reglamento 1347/2000 únicamente se ocupaba (al igual que el Convenio de 28 de mayo de 1998) de la responsabilidad parental respecto de los hijos comunes atendiendo precisamente a su estrecha vinculación con la disolución de la pareja, sin embargo, el Reglamento 2201/2003 incluye a los hijos no comunes que forman parte de la familia. Vid., R. Arenas García, Crisis matrimoniales...op.cit., p. 159-165. 
parenta $1^{10}$ y el resto resultan reguladas por otros instrumentos comportando, también, una potencial disociación de la competencia de los Tribunales. De hecho, podría suceder que los tribunales españoles fueran competentes para conocer de la disolución del vínculo matrimonial pero no respecto a otras cuestiones conexas, $\mathrm{y}$ al revés ${ }^{11}$.

En relación a lo anterior, debemos precisar que las pretensiones de la demandante, aunque están dirigidas a modificar las medidas establecidas en una Sentencia de divorcio anterior, y, por tanto, unidas en ese sentido a la disolución del vínculo matrimonial, se solicitan en un nuevo procedimiento que versa únicamente sobre la responsabilidad parental. Se analiza la competencia de los tribunales españoles para conocer una demanda concerniente a la modificación de la potestad parental establecida en una decisión previa, pudiendo haber sido los tribunales rumanos los competentes para resolver el divorcio y establecer dichas medidas de responsabilidad parental en el instante en que se planteó la nueva organización familiar. Este dato tendría importancia ante la eventualidad de atender a la perpetuatio jurisdictionis para otorgar la competencia al mismo tribunal del Estado miembro del que emanó la resolución judicial que establecía las medidas que se quieren modificar prevista en el Reglamento Bruselas II bis; pero esta posibilidad la trataremos más adelante al analizar los foros de competencia.

7. Volviendo al ámbito material, y teniendo en cuenta que en la demanda se solicita la modificación de las medidas sobre el régimen de visitas de la menor y el incremento de la pensión de alimentos impuesta con anterioridad, la clave se halla en el concepto de "responsabilidad parental" del Reglamento Bruselas II bis. El Reglamento Bruselas II bis establece una definición amplia de "responsabilidad parental" mediante la que cubre todos los derechos y obligaciones de su titular en relación con la persona o los bienes de un menor (Art. 2.7 RBIIbis) ${ }^{12}$. Más concretamente, el Reglamento Bruselas II bis se aplica tanto a la atribución y a la modificación, como a la finalización de la responsabilidad parental (art. 1.1. b) RBIIbis) de aquellas medidas adoptadas en las materias enumeradas en su artículo 1.2 RBIIbis. En particular, entre estas materias se halla el derecho de custodia y visita. Como podemos observar, se establece una definición autónoma propia del instrumento europeo que evita acudir a los ordenamientos nacionales ${ }^{13} \mathrm{y}$, conforme a ella, se concluye que las modificaciones de las medidas sobre el régimen de visita solicitadas por la madre entran, sin lugar a duda, dentro de su ámbito de aplicación ${ }^{14}$.

8. No sucede lo mismo con la segunda de las cuestiones objeto de la demanda: el incremento de la pensión de alimentos. En el artículo 3.2 RBIIbis se especifican las materias que se excluyen del ámbito de aplicación del Reglamento Bruselas II bis y entre ellas se encuentra la pensión de alimentos. Los alimentos para los hijos se regulan en el Reglamento 4/2009 del Consejo de 18 de diciembre de 2008, relativo a la competencia, la ley aplicable, el reconocimiento y la ejecución de las resoluciones y la cooperación en materia de obligaciones de alimentos (Reglamento 4/2009) ${ }^{15}$. A pesar de ello el establecimiento de la pensión alimenticia también está estrechamente relacionado a los derechos de custodia

${ }^{10}$ A. Borras Rodríguez, en "Competencia judicial, reconocimiento y ejecución de decisiones en materia matrimonial: el Reglamento 1347/2000 de 29 de mayo (Bruselas II)”, RJC, 2003, año CII, No 2, pp. 361-389, nos recuerda que la introducción de la responsabilidad parental en el Convenio de 28 de mayo de 1998 sobre competencia judicial internacional, reconocimiento y ejecución de resoluciones judiciales en materia de crisis matrimoniales y responsabilidad parental, fue fruto de la iniciativa de España y Francia que entendían que resultaba esencial que el juez que estuviera conociendo de la cuestión matrimonial se pronunciase igualmente sobre los efectos que puede tener sobre los hijos, p. 369; "Informe explicativo del Convenio celebrado con arreglo al artículo K3 del Tratado de la Unión Europea sobre la competencia, el reconocimiento y la ejecución de resoluciones judiciales en materia matrimonial preparado por la Profesora Dña. Alegría Borrás”, (Informe Borrás), DOCE n C221, de 16 de julio de 1998, nº 23 y 24.

11 R. Arenas Gracia, Crisis matrimoniales...op.cit., pp. 141-171.

12 Vid., Guía Práctica de aplicación del Reglamento Bruselas II bis. A pesar de esta enumeración se han producido diferentes pronunciamientos del TJUE que delimitan el ámbito de aplicación del RBIIbis: STJCE 27 noviembre de 2007, C-435/06, $C$; STJUE 2 abril de 2009, C-523/07, A; STJUE 21 de octubre 2015, C-215/15, Gogova.

13 A diferencia del Reglamento 1347/ 2001 y del Convenio de 1998.

14 Vid., Auto del TJUE 3 de octubre de 2019, C-759/18, Of vs. PG, apdos. 48-54. El concepto de "derechos de custodia" se define en el artículo 2.9 del RBIIbis como los derechos y obligaciones relativos al cuidado de la persona de un menor y, en especial, el derecho a decidir sobre su lugar de residencia.

15 DOUE L7 de 10 de enero de 2009. 
y visita de la pareja y, con frecuencia, se negocian en los mismos procesos judiciales entre progenitores, así que el razonamiento esgrimido en el Considerando 8 sobre la inclusión de la responsabilidad parental en el RBIIbis se podría extender igualmente a la materia de alimentos ${ }^{16}$. Tal y como establece el Tribunal de Justicia de la Unión Europea, la propia naturaleza de la obligación de alimentos a favor de hijos menores se halla intrínsecamente vinculada con la acción relativa a la responsabilidad parental. De todas formas aunque la demanda relativa a la pensión alimenticia de un menor pueda ser considerada como naturalmente accesoria a la responsabilidad parental, ello no debe comportar una minusvaloración de su autonomía material ${ }^{17}$.

\section{El carácter accesorio y alternativo de la pensión alimenticia en aras a establecer el foro de competencia}

9. Como ya se ha indicado en el epígrafe anterior la competencia judicial internacional en materia de pensión de alimentos se regula de manera específica y autónoma en el Reglamento 4/2009. El Reglamento 4/2009, mediante el artículo 3, instaura varios foros alternativos entre los que se encuentran los apartados c) y d) donde incluye la posibilidad de que el demandante, al solicitar la pensión alimenticia, acuda al órgano jurisdiccional competente para conocer la disolución del vínculo matrimonial o al foro competente para resolver las cuestiones de responsabilidad parental. De este modo, atiende a la congruencia de conocer en el mismo proceso de crisis matrimonial o de responsabilidad parental la acción de alimentos. En este caso en concreto, la competencia se establece conforme al RBIIbis (analizada en el siguiente epígrafe) y permite al demandante concentrar el litigio en un único tribunal e interponer la demanda ante el foro de responsabilidad parental. En relación con la responsabilidad parental el demandante puede elegir ante qué foro acudir y sopesar si prefiere dar prioridad a la optimización de recursos vinculada a la concentración del litigio en un solo foro, por encima de las ventajas de interponer la demanda en la residencia habitual del demandado como lugar donde el deudor de alimentos suele tener bienes, o en su propia residencia habitual con las ventajas de acceso que se le presuponen ${ }^{18}$. En el supuesto objeto del presente comentario la residencia del demandado está en España y, por tanto, coincide con el lugar donde la demandante ha incoado el procedimiento en virtud de la residencia habitual de la menor, así que no concurre esa dualidad.

10. Tampoco se plantean dudas acerca de la "accesoriedad" de la pensión de alimentos respecto a la acción de responsabilidad parental puesto que se solicita en un procedimiento posterior a la disolución del vínculo matrimonial y en el que la modificación de la custodia sobrelleva naturalmente una alteración de la pensión alimenticia. Desde el punto de vista de la competencia judicial, la concentración en un mismo tribunal de las acciones sobre responsabilidad parental y alimenticia, cuenta con la enorme ventaja de atender de un modo integral a la situación del menor. El juez competente para conocer las acciones sobre responsabilidad parental establecerá el modelo de custodia (compartida o exclusiva) así que tendrá conocimiento de los elementos facticos sobre el ejercicio de la responsabilidad parental y, en función de ello, podrá fijar los gastos de manutención y educación, así como el derecho de visita ${ }^{19}$. Consideramos que, en el asunto que nos concierne, la decisión de la madre de interponer la demanda de responsabilidad parental y de pensión alimenticia ante un mismo foro asevera la competencia del

${ }^{16}$ Como pone de manifiesto A. BorrÁs, "Bruselas II, Bruselas II bis, Bruselas ter...”, REEI, $\mathrm{n}^{\circ}$ 38, diciembre 2019, pp. $1-5$, p. 2.

${ }_{17}$ STJUE 16 de julio de 2015, C-184/14, $A$, apdo. 48.

18 C. GonzÁlez Beilfuss, "La nulidad, separación y divorcio en el Derecho internacional privado español: cuestiones de competencia judicial internacional y ley aplicable", Cursos de Derecho Internacional y relaciones internacionales de Vitoria Gasteiz, Universidad del País Vasco, Aranzadi, no 1, 2011, pp. 135-194, p. 166. La protección del acreedor se proyecta sobre la posibilidad de escoger entre los foros y elegir el que más se adecúe a sus intereses, no sólo desde el punto de vista de la competencia judicial, sino también de las soluciones de Derecho aplicable, vid., S. Álvarez González, Crisis matrimoniales y prestaciones alimenticias entre conyuges, Civitas, Madrid, 1996, p. 31.

19 STJUE 16 de julio de 2015, C-184/14, $A$, apdo. 40-42. 
mismo tribunal para conocer ambas cuestiones en virtud del concepto de "demanda accesoria". En este supuesto no caben dudas de la utilización del concepto de "demanda accesoria" que figura en el artículo 3 d) como concepto autónomo e intrínsecamente ligado a la acción relativa a la responsabilidad parental, así que no se producen divergencias hermenéuticas ${ }^{20}$.

\section{La residencia habitual: un concepto flexible y adaptable caso por caso}

11. Una vez se ha determinado que el instrumento aplicable para establecer la competencia de los tribunales españoles en aras a conocer la demanda sobre responsabilidad parental y, accesoriamente, sobre la pensión alimenticia es el Reglamento Bruselas II bis, atenderemos al criterio de la residencia habitual sobre el que instaura sus cimientos tanto para establecer la competencia con carácter general (art. 8 RBIbis) como en situaciones excepcionales (arts. 9 y 10 RBIIBis) ${ }^{21}$.

El artículo 8 RBIIBis otorga la competencia judicial en materia de responsabilidad parental con carácter general a los órganos jurisdiccionales de la residencia habitual del menor en el momento en el que se presenta la demanda. Las dudas surgidas en el presente Auto de la Audiencia Provincial de Barcelona giran en torno a su determinación y a los elementos facticos que debemos tener en cuenta para concretarla. El Reglamento Bruselas II bis carece de una definición específica de residencia habitual y esa omisión puede generar, en ocasiones, una sensación de inseguridad jurídica y un mayor protagonismo de la labor de los operadores jurídicos. El legislador europeo ha optado por un concepto abierto, adaptable a cada situación, que nos permite atender a la gran variedad de escenarios que se producen como consecuencia de la creciente movilidad geográfica en Europa y una definición general llevaría, precisamente, a perder ese carácter ${ }^{22}$. La residencia habitual del menor es un concepto factico que indica el lugar en el que una persona fija de manera voluntaria y estable su centro de vida social y familiar ${ }^{23}$.

12. Por otra parte, se trata de una noción que ha de gozar de un significado autónomo, uniforme y específico del Reglamento Bruselas I bis ${ }^{24}$ y alejarse de los particularismos jurídicos nacionales, así que la ayuda del Tribunal de Justicia de la Unión Europea ha sido fundamental para ir dando pautas comunes en torno a su determinación y a las circunstancias que contribuyen a ir consolidando los elementos básicos inherentes al concepto europeo ${ }^{25}$.

\footnotetext{
${ }^{20}$ Sobre el concepto de "demanda accesoria" de la acción de alimentos, vid., STJUE 6 de julio de 2015, C-184/14, comentarios en C.I. Cordero Álvarez, "Sentencia del TJUE (sala $3^{\text {a }}$ ), de 16 de julio de 2015, asunto C-184/14 a y B", REDI, vol. 68 (2016), 1, pp. 178-181 y J. J. VARA PARra, "Una reflexión sobre el alcance del foro de accesoriedad. Sentencia del Tribunal de Justicia (sala Tercera) de 16 de julio de 2015, asunto C-184/14", La Ley Unión Europea, $\mathrm{n}^{\mathrm{0}}$ 31, 30 de noviembre de 2015. Se abre un interesante debate sobre la accesoriedad y alternatividad de la demanda de alimentos respecto a la demanda de disolución del vínculo matrimonial o respecto a la de responsabilidad parental en la STJUE 5 de septiembre de 2019, C-468/18, $R$ vs. $P$, vid., I. Rodríguez-Uría SuÁrez, "Competencia judicial internacional en materia de alimentos debido a menores. Alternatividad y accesoriedad en el Reglamento 4/2009”, La Ley Unión Europea, n 78, febrero 2020.

${ }^{21}$ La residencia habitual atiende a una doble función, como establece C. CHALAs, "Précisions su la résidence habituelle et la procédure de retour de l'enfant dans le règlement Bruxelles II bis", $R C D I P, \mathrm{n}^{\circ}$ 1, 2018, pp.115-125, p.117; sobre la residencia habitual en los instrumentos de Derecho Internacional Privado europeo vid., A. RodRíGuez Benot, "El criterio de conexión para determinar la Ley personal: un debate renovado de Derecho Internacional privado", CDT, 2010, Vol. 2, No 1, pp. $186-202$.

${ }^{22} \mathrm{Vid}$., El Reglamento Bruselas II ter tampoco acota la definición de residencia habitual del menor. En ese sentido A. BoRRÁs, “Bruselas II, Bruselas II bis, Bruselas ter...”, REEI; n 38, diciembre 2019, p. 5. A favor de una mayor concreción vid., L. A. Pérez Martin, "El interés superior de los niños y las niñas de nuevo sobre la necesidad de la creación del concepto autónomo de su residencia habitual. Auto de 24 de octubre de 2019, sección decimosegunda de la Audiencia Provincial de Barcelona", CDT, 2021, vol. 12. № 2, pp. 119-1127.

${ }^{23}$ Informe "Borrás", no 32.

${ }^{24}$ Es una definición que no se puede extraer de la interpretación de otros Reglamentos: STJUE 2 abril de 2009, C-523/07, C-523/07, A, apdo. 36. Vid., R. CARo GandarÁ, "La determinación de la residencia habitual del demandante y de los menores en litigios sobre crisis matrimoniales y responsabilidad parental”, en Reflexiones jurídicas sobre cuestiones actuales, J.A. Robles Garzón, (coord.), Aranzadi, Cizur Menor, 2017, pp. 161-174.

${ }_{25}$ STJUE 17 de octubre 2018, C-393/18 PPU, UD, vs. XB; STJUE 8 de junio 2017, C-111/17 PPU, OL, vs $P Q$; STJUE 9 octubre 2014, C-376/14 PPU, C-M; STJUE 22 diciembre 2010, C-497/10 Mercredi.
} 
13. Tal y como se percibe en el Auto que comentamos, el establecimiento de la residencia habitual del menor resulta una cuestión compleja que deberá atender al caso particular y que se va a solventar de manera distinta según los elementos de hecho presentes en el litigio. De esta forma se convierte en un criterio variable del que debemos extraer un sustrato común ${ }^{26}$. En ocasiones resulta complicado determinar dónde tiene la residencia habitual el menor, en especial cuando la familia se ha movido geográficamente de un Estado a otro provocando su desplazamiento, y nuestro supuesto puede servir como ejemplo. La Sentencia de Instancia objeto de apelación considera que los órganos jurisdiccionales españoles carecen de competencia porque la residencia habitual de la menor se encuentra en Rumania en atención al último lugar donde ha cursado sus estudios y, en cambio, la demandante recurre esa decisión alegando que la residencia habitual de la menor está en España, para lo que aporta como prueba el certificado del padrón.

14. Para resolver los inconvenientes interpretativos derivados de una definición más específica, es menester extraer unas pautas hermenéuticas básicas atendiendo, por un lado, al objetivo que persigue la norma y, por otro, al contexto en el que se inserta.

En primer lugar, debemos subrayar que la residencia habitual del menor, como criterio clave del Reglamento Bruselas I bis, se fundamenta en el principio de protección del interés del menor así que su interpretación, desde un punto de vista teleológico, deberá tender igualmente a garantizarla. Tal y como se desprende del tenor del considerando 12 del Reglamento Bruselas II bis, esta garantía va unida al criterio de proximidad. En un principio, las autoridades del país de la residencia habitual del menor son las que están mejor situadas para conocer y acceder al medio social del menor, las que pueden adoptar decisiones con mayor rapidez y, además, producen un efecto disuasorio del traslado ilícito ${ }^{27}$.

Bajo esta orientación del concepto de residencia subyace el principio de integración social y/o familiar del menor en un determinado Estado miembro ${ }^{28}$ del que parece desprenderse la estabilidad o regularidad que convierten a la residencia en "habitual" en contrapartida a la residencia ocasional o temporal ${ }^{29}$. Entre los factores que manifiestan permanencia escogemos algunos de los establecidos por el Tribunal de Justicia y que se encuentran en el Auto que nos ocupa para destacarlos como indicios positivos de integración de la menor: la duración, la regularidad, la nacionalidad de la menor, los conocimientos lingüísticos y las condiciones de escolarización ${ }^{30}$. Tales circunstancias se aprecian en nuestro supuesto y, en un principio, conectan a la menor con Rumania lo que nos podrían llevar a descartar la competencia de los tribunales españoles y suscribir la de los Tribunales rumanos, tal y como hace en este supuesto el Tribunal de Instancia.

15. En segundo lugar, deberemos atender a la interpretación sistemática, que pone el acento en la necesidad de perfilar la definición caso por caso y de ponderar otras circunstancias que pueden prevalecer sobre las anteriores incrementando la complejidad inherente al criterio de residencia habitual en su proyección a la práctica. En este sentido, se requiere hacer un análisis global y una evaluación en conjunto en el que pueden cobrar fuerza otro tipo de factores: las condiciones de la estancia o del traslado, la presencia física del menor o la voluntad de permanencia, con independencia del tiempo que la menor lleva alli ${ }^{31}$. En el Auto de la Audiencia Provincial de Barcelona observamos que la discrepancia entre

${ }^{26}$ A. Richez Pons "Habitual residence consideradas an european harmonisation factor in family law (regarding the Brussels II-bis Regulation", en K. Woele-Boelki, Common Core and Better Law in European Family Law, Intersentia, Antwerpen, 2005 , pp. 355-360.

27 A. Calvo Caravaca y J. Carrascosa, Tratado de Derecho Internacional Privado, T II, Tiran lo Blanch, Valencia, 2020, p. 2033y 2034; STJUE 15 julio de 2010, C-256/09, Purrucker, apdo. 91; vid., P. Lagarde, "Le príncipe de proximité dans le droit international privé contemporain", RCADI, 1986-1, t. 196.

28 STJUE 2 abril 2009, C-523/07, A, apdo.44; STJUE 22 diciembre 2010, C-479/10, Mercredi, apdo. 44.

29 STJUE 22 diciembre 2010, C-479/10, Mercredi apdo.49 y STJCE 2 abril 2009, C-523/07, A, apdo. 48.

30 STJUE 2 abril 2009, C-523/07, $A$, apdo. 39.

31 Vid., M. Guzmán Peces, "Problemática en la coordinación de los instrumentos normativos aplicables a la sustracción de menores y en particular a la interpretación de la residencia habitual", $A E D I P r$, t. XIV-XV, 2014-2015, pp. 489-522, p. 510-512; STJCE 2 abril 2009, C-523/07, A, apdos. 35-44; STJUE 17 octubre 2018, C-393/18, UD, apdo. 62; STJUE 22 diciembre 2010, C-479/10, Mercredi apdo. 51. 
los tribunales se origina, en cierto modo, en la estimación temporal de la residencia habitual de la menor que, tras terminar el curso en Rumania, se ha desplazado con su madre a España donde se ha iniciado el procedimiento. En este caso, el elemento de estabilidad va a depender de la voluntad de permanencia y no de la cuantificación del tiempo que lleva la menor en el país, y la demandante demuestra dicha voluntad mediante la inscripción del padrón. La inscripción en registros formales no es por sí sola un indicio determinante, pero puede considerarse en este caso un elemento positivo junto a otros factores.

16. El desplazamiento de la menor con anterioridad a la interposición de la demanda afecta a la competencia en tanto comporta una nueva residencia habitual que supone la pérdida de la anterior. La presencia estable y duradera durante un determinado periodo de tiempo refleja un vínculo real con el medio social, pero tampoco es un valor definitivo y puede variar dependiendo del caso particular ${ }^{32}$. De hecho, el Reglamento Bruselas II bis no establece un intervalo temporal para acotar la residencia y, aunque el término "habitual" podría indicar la necesidad de cierta duración del vínculo antes de que se pueda calificar de "habitual", no se excluye la posibilidad de que un menor adquiera esa residencia el mismo día de su llegada o poco después si existe voluntad de asentar el centro de intereses de manera estable $^{33}$. Así sucede en el caso objeto de comentario en el que dotar de prevalencia al criterio cualitativo frente al cuantitativo nos conduce a señalar la residencia habitual de la menor en España.

17. Igualmente, aunque no se ve reflejada esta posibilidad en los fundamentos de derecho del Auto de la Audiencia, podría suceder que la menor se hubiera trasladado a Rumania temporalmente a cursar sus estudios mientras sus progenitores permanecían en España y, en ese caso, la presencia del núcleo familiar en España sería suficiente para avalar a la vuelta su integración familiar y la residencia habitual de la menor en ese país.

\section{La perpetuatio jurisdictionis en el Reglamento Bruselas II bis}

18. Para finalizar, vamos a realizar un breve comentario de la perpetuatio fori en el Reglamento Bruselas II bis. Es menester subrayar, que la cuestión de la competencia se determina en el momento en el que se interpone la demanda ante el órgano jurisdiccional y, una vez iniciado el proceso, dicho órgano retiene la competencia mientras perdure ${ }^{34}$. Ello comporta que, aunque el menor cambie de residencia habitual, no se modifica la jurisdicción de los tribunales ${ }^{35}$. En este sentido, la competencia se deberá establecer en cada caso particular y no se mantiene finalizado el procedimiento ${ }^{36}$. Los tribunales competentes para llevar un procedimiento en la que se plantea, por ejemplo, la disolución del vínculo de la pareja, el establecimiento de la responsabilidad parental y la pensión de alimentos no tienen por qué seguir siéndolo para conocer una demanda posterior de modificación de esas medidas de responsabilidad parental y de obligaciones de alimentos si la residencia del menor se encuentra en el territorio de

\footnotetext{
32 Sobre la presencia física: C. Chalas, "Précisions...,", op.cit., pp. 117-123.

33 Tal y como pone en valor la Guia práctica de aplicación del Reglamento Bruselas II bis, p. 27, también, A. Richez-Pons, "Habitual residence considerated an european harmonisation factor in family law (regarding the Brussels II-bis Regulation", en K. Woele-Boelki, Common Core and Better Law in European Family Law, Intersentia, Antwerpen, 2005, pp. 355-360.

${ }^{34}$ SJUE 1 octubre de 2014, C.463/13, E., apdo. 38. En este sentido según dispone el artículo 16 del Reglamento Bruselas II bis se considerará iniciado un procedimiento ante un órgano jurisdiccional desde el momento en el "que se le presenta el escrito de demanda".

${ }_{35}$ Las dificultades prácticas que se derivan de la aplicación del principio de perpetuatio fori se basan en la distancia geográfica entre el nuevo lugar de "residencia habitual" del niño y el tribunal que sigue siendo responsable de la causa. Si el proceso se lleva a cabo en un Estado miembro donde el menor no tiene su residencia habitual, es posible que el menor tenga que viajar durante el proceso, tal y como se pone de manifisto en "Study on the assesment of Regulation (EC) n $\mathrm{n}^{\mathrm{O}} 2201 / 2003$ and the policy options for its amendmen, Final Report”, p. 29. Cabe destacar que, en la situación actual, un tribunal de un Estado miembro conservaría la jurisdicción si el menor se ha trasladado a otro Estado miembro de la UE, pero perderá la jurisdicción si el menor se ha trasladado a otro Estado contratante del Convenio de La Haya que no sea de la UE. Estado miembro (o no un Estado miembro del Reglamento Bruselas II bis como Dinamarca), p. 30.

36 STJUE 1 octubre de 2014, C.463/13, E., apdo. 40.
} 
otro Estado miembro. En atención a lo anterior, en la resolución que trae causa, carece de relevancia que la sentencia de divorcio en la que se establecieron las medidas previas de responsabilidad parental y de alimentos que se quieren modificar tuviera su origen en Rumania, poniéndose de manifiesto la potencial disociación de la competencia judicial.

19. Otra cuestión diferente será si, en ocasiones, es oportuno mantener la competencia del Estado miembro de la residencia habitual del menor para modificar un régimen de responsabilidad parental que han establecido los tribunales de ese país antes de su traslado ${ }^{37}$. El artículo 9 del Reglamento Bruselas II bis prevé esta posibilidad cuando un menor se desplaza a otro país y, de acuerdo a esa nueva circunstancia, resulta necesario modificar los acuerdos previamente establecidos; entonces sí recomienda a los titulares de la responsabilidad parental realizar los ajustes necesarios con anterioridad al traslado ${ }^{38}$. Pero se trata de una excepción a la regla general muy limitada y, como tal, debe cumplir una serie de requisitos establecidos por la norma ${ }^{39}$, así que no es necesario plantearlo en este supuesto.

\section{Consideraciones finales}

20. La decisión que ha servido de base a este comentario nos ha permitido reparar en la complejidad del entramado normativo existente en el Derecho de familia europeo que, por un lado, integra conjuntamente en un mismo instrumento las normas relativas a las crisis matrimoniales y a la responsabilidad parental pero, por otro, desarrolla mediante regulación específica cuestiones igualmente conexas a un proceso de disolución del vínculo de la pareja como la pensión alimenticia (o la disolución del régimen económico patrimonial). La primera dificultad con la que se encuentra el operador jurídico es la de determinar la normativa aplicable para establecer la competencia en materia de responsabilidad parental ante la concurrencia de diversos textos normativos con distinto origen y alcance. Esta fragmentación parte del limitado ámbito de aplicación del Reglamento Bruselas II bis que se aplica a la disolución, relajación y anulación del vínculo matrimonial y a la responsabilidad parental, pero deja fuera otras cuestiones permitiendo una potencial disociación material de tribunales competentes que, a pesar de que ha sido criticada por la incertidumbre legislativa que soporta, proporciona un nivel de especialización y de desarrollo en distintas velocidades que no debe ser desdeñado.

21. Una de las cuestiones que el Reglamento Bruselas II bis extrae de su ámbito de aplicación material es la pensión alimenticia que goza de una regulación autónoma. A pesar de lo cual el Reglamento 4/2009 posibilita al demandante elegir la concentración ope legis cuando así lo estime acorde con sus intereses.

22. Entre las dificultades que se derivan de la aplicación del Reglamento Bruselas II bis resalta la determinación del concepto de residencia habitual del menor que se erige en criterio vertebrador del Instrumento europeo, tal y como se refleja en la numerosa jurisprudencia del Tribunal de Justicia existente al respecto. Es cierto que, hay ocasiones en los que resulta complicado establecer la residencia habitual del menor cuando ha sufrido varios traslados por diferentes Estados, pero también que los criterios hermenéuticos que subyacen a la norma son claros y que el Tribunal de Justicia de la Unión ha ido dotando de herramientas oportunas que pueden ayudar a los tribunales de los Estados miembros

\footnotetext{
${ }^{37}$ Al respecto vid., A. Borrás, “Article 9”, en Brussels II bis Regulation, U. Magnus y P. Mankowski, Sellier, European law publishers, UK, 2012, pp. 116-119.

${ }^{38}$ Guía Práctica de aplicación del Reglamento Bruselas II bis.

39 Vid., S. Corneloup, "Les règles de compètence relatives à la responsabilité parentale", en H. Fulchiron y C. Nourissat (dres.) Le nouveau droit communautaire du divorce et de responsabilité parentale, Dalloz, 2005, pp. 69-84, p. 75; D. GLUHAIA, "Residencia Habitual del menor y tribunales competentes para modificar una resolución judicial sobre derecho de visita. Aplicación jurisprudencial de los arts. 8 y 9 del Reglamento 2201/2003”, CDT, 2019, Vol. 11, No 1, pp. 751-757; A. QuIÑONES EsCAMEZ, "Competencia judicial internacional en materia de responsabilidad parental y sustracción internacional de menores en el Reglamento 2210/2003, La Ley, 16212/2008, p. 3.
} 
a realizar una correcta valoración al respecto. De hecho, en la decisión de la Audiencia Provincial de Barcelona que ha dado lugar al presente trabajo no se ha puesto de manifiesto tal grado de complejidad y sí, cierta dejadez o desconocimiento del Juzgado de Primera Instancia que no parece haber realizado una detenida ponderación de los elementos facticos que concurrían en el litigio en particular. 